\title{
Long-term care and lazy rotten kids ${ }^{1}$
}

\author{
Helmuth Cremer \\ Toulouse School of Economics \\ Kerstin Roeder \\ LMU, Munich
}

February 2013, revised August 2013

${ }^{1}$ Financial support from the Chaire "Marché des risques et creation de valeur" of the FdR/SCOR is gratefully acknowledged. This paper has been presented at the European Health Economics Workshop, the Public Economic Theory Conference, the Journées d'Economie Publique Louis-André Gérard-Varet and in seminars at the Universities of Munich, and Constance. We thank all the participants for their comments. We are particularly grateful to Justina Klimaviciute for her insightful remarks and suggestions. 


\begin{abstract}
This paper studies the determination of informal long-term care (family aid) to dependent elderly in a worst case scenario concerning the "harmony" of family relations. Children are purely selfish, and neither side can make credible commitments (which rules out efficient bargaining). The model is based on Becker's "rotten kid" specification except that it explicitly accounts for the sequence of decisions. In Becker's world, with a single good, this setting yields efficiency. We show that when family aid (and long-term care services in general) are introduced the outcome is likely to be inefficient. Still, the rotten kid mechanism is at work and ensures that a positive level of aid is provided as long as the bequest motive is operative. We identify the inefficiencies by comparing the laissez-faire (subgame perfect) equilibrium to the first-best allocation. We initially assume that families are identical ex ante. However, the case where dynasties differ in wealth is also considered. We study how the provision of long-term care (LTC) can be improved by public policies under various informational assumptions. Interestingly, crowding out of private aid by public LTC is not a problem in this setting. With an operative bequest motive, public LTC will have no impact on private aid. More amazingly still, when the bequest motive is (initially) not operative, public insurance may even enhance the provision of informal aid.
\end{abstract}

Keywords: Rotten kids, long-term care, family aid, optimal taxation

JEL-Classification: D13, H21, I13 


\section{Introduction}

Long-term care (LTC) concerns people who depend on help to carry out daily activities such as eating, bathing, dressing, going to bed, getting up or using the toilet (OECD, 2005). It is delivered informally by families - mainly spouses, daughters and stepdaughters - and, to a lesser extent, formally by care assistants, who are paid under some form of employment contract. Formal care is given at home or in an institution (such as care centers and nursing homes). The governments of most industrialized countries are involved in either the provision or financing of LTC services, or often both, although the extent and nature of their involvement differs widely across countries. ${ }^{1}$

In the future, the demand for formal LTC services by the population is likely to grow substantially. LTC needs start to rise exponentially from around the age of 80 years. The number of persons aged 80 years and above is growing faster than any other segment of the population. As a consequence, the number of dependent elderly at the European level (EU-27) is expected to grow from about 21 million people in 2007 to about 44 millions in 2060 (European Commission, 2009). We thus anticipate increasing pressure on resources demanded to provide LTC services for the frail elderly, and this pressure will be on the three institutions currently financing and providing LTC services: the state, the market and the family.

To assess the adequacy of LTC financing and provision and to make projections, it is important to assess he extent to which countries will be able in the future to rely on the informal provision of care. Most seniors with impairments reside in their home or that of their relatives, and they rely largely on volunteer care from family members. These include seniors with severe impairments (unable to perform at least four activities of daily living). An important feature that is often neglected is the real motivation for family solidarity. For long, we have adopted the fairy tale view of children or spouses helping their dependent parents with joy and dedication, what we call pure altruism. We now increasingly realize that family solidarity is often based on forced altruism (social norm) or on strategic considerations (e.g., Cox 1987; Cox and Rank, 1992; Canta and Pestieau, 2013). ${ }^{2}$

\footnotetext{
${ }^{1}$ For a more in-depth discussion see the overview by Cremer, Pestieau and Ponthière (2012).

${ }^{2}$ Either way family care goes along with disutility and forgone labor market opportunities for the care-giving person. See, for instance, Bolin, Lindgren and Lundborg, (2008); Hughes et al. (1999); and Schulz and Beach, (1999).
} 
Knowing the foundation of altruism is very important to see how family assistance will react to the emergence of private or public schemes of LTC insurance. For example, the introduction of LTC social insurance is expected to crowd out family solidarity based on pure altruism (e.g., Cremer, Gahvari and Pestieau, 2013). On the other hand, where "solidarity" is based on strategic exchanges crowding out is expected to be less significant. Its precise extent, is then likely to depend on the specific way these interfamily exchanges are determined. The existing literature (e.g., Bernheim, Shleifer, and Summers, 1985) concentrates on strategic bequest type models with full commitment leading to efficient bargaining. In reality this appears to be a rather strong assumption.

In this paper, we study the determination of family aid in what can be considered a worst case scenario as to the "harmony" of family relations. Children act in a purely selfish way and neither side can make credible commitments (which would open the possibility of efficient bargaining as in the strategic bequest setting). The model we use is based on Becker's (1974; 1991) "rotten kid" specification (see also Bergstrom, 1989; 1996) except that we explicitly account for the sequence of decisions (like Bruce and Waldman, 1990). In Becker's world, with a single good, this setting yields an efficient outcome, even in the absence of commitment and when a child is purely selfish. We show that when family aid (and LTC services in general) are introduced the outcome is likely to be inefficient. This is particularly true when the parents value their children's care more than the market substitutes. ${ }^{3}$ Still, the rotten kid mechanism is at work and ensures that a positive level of aid is provided as long as the bequest motive is operative. We study how the inefficiency can be corrected by public policies under various informational assumptions. For most of the paper, we assume that families are identical ex ante. However, the case where dynasties differ in wealth is also considered.

The design of public policy has to account for the (in)efficiencies of informal aid. The conventional wisdom is that public policy often creates or at least enhances such inefficiencies through crowding out. In our setting, however, the relationship between public LTC and family aid is more complex. As long as the bequest motive is operative, the children do provide some informal aid to their parents, but its level is too low, except when the full impact of aid is captured by its monetary valuation in the parent's

\footnotetext{
${ }^{3}$ It was already pointed out by Bergstrom (1989) that Becker's rotten kid theorem holds if there is one commodity (money), the parent is an effective altruist and chooses after the child (for this see also Hirshleifer, 1977), and the model is static. For a summary of cases when the rotten kid theorem fails see also Laferrère and Wolff (2006).
} 
utility. Children's labor supply is then also inefficient, but this problem is not directly connected to the potential need for LTC. When the bequest motive is not operative, no family aid will be provided and the case for public intervention will be even stronger. Interestingly, this failure of family aid may effectively be related to private market inefficiencies. Particularly, an individual who cannot afford to buy insurance coverage to cover the potential monetary cost of LTC may be subject to a "double punishment". In case of dependency the individual will not only run out of resources, but he can also not count on any family aid (since he has no resources to leave a bequest). Public aid may then even result in a positive bequest and thus bring about a positive level of aid. To sum up, crowding out of private aid by public LTC is not a problem in this setting. With an operative bequest motive, public LTC will have no impact on private aid. More amazingly still, when the bequest motive is (initially) not operative, public insurance may even enhance the provision of informal aid.

Public intervention in LTC is often advocated because it might help to overcome inefficiencies in the private insurance market. ${ }^{4}$ When, as is typically observed in reality, private LTC insurance involves significant loading costs (Brown and Finkelstein, 2007), the laissez-faire solution implies insufficient insurance. Public insurance may mitigate this problem but once again its effectiveness will hinge on the extent of crowding out of family aid. For the sake of realism we consider the possibility that private insurance may involve loading costs, but this is not the driving force behind our results.

Either way, the effectiveness and the design of public LTC depend on the available instruments which is ultimately of course a question of information. We first study the implementation of the first-best (FB) under full information. Though of limited realism this is an interesting benchmark to show which instruments are necessary within this setting of multi-stage strategic interaction to achieve the efficient solution. We show that the FB can be decentralized by a lump-sum transfer from the dependent to the healthy elderly supplemented by linear subsidies on labor incomes (of the young) and aid. Lump sum transfers are determined to mimic fair private insurance. Next, we look at a second-best solution which is achieved when aid is not observable (and thus cannot not be subsidized). The set of instruments now consists of a lump-sum tax on the healthy old and linear taxes on child's income that both finance public LTC provision

\footnotetext{
${ }^{4}$ See e.g. Siciliani (2013) for a discussion of the relative merits of public and private insurance.
} 
to dependent parents. We show that transfers are used to achieve full insurance of the old. The tax on labor, on the other hand, is not used to raise revenue, but because it increases informal aid (which becomes more attractive when market labor is taxed). If possible the tax on children's labor supply should be differentiated according to the dependency status of their parents. The level of the tax on the children of dependent parents is then set to strike a balance between the deadweight loss of the labor tax and the benefits associated with its effect on aid (a tax on labor effectively acts like a subsidy on aid). Children of healthy parents, on the other hand, benefit from the first-best subsidy on labor.

Finally, we turn to a setting where individuals are heterogenous and parents differ in wealth. This adds an extra potential justification for public intervention, namely redistribution. It also makes a case where some individuals cannot afford private LTC coverage more plausible and we can have an initial equilibrium in which the bequest motive is operative for some individuals and not for others. To concentrate on distributional issues, we assume that the government does not observe wealth, while all other variables are observable. We consider a two-types setting and study the second-best allocation achieved under this information structure. We show that bequests in rich families are not distorted (neither taxed nor subsidized at the margin), but there is a downward distortion on bequests in poor families. In other words, bequests left by low wealth parents are subject to a positive marginal tax. This result is in line with standard findings in optimal tax models (Mirrlees, 1971). More surprisingly, the solution implies a first-best tradeoff for labor supply and informal care. Interestingly, this first-best tradeoff does not imply the same marginal tax rates on labor or aid as in the decentralization of the first-best under full information. This is because the bequest tax affects also labor supply and aid decisions and the tax or subsidy rates have to be adjusted accordingly. Finally, high wealth individuals are fully insured; the insurance provision to the low wealth parents, on the other hand is distorted (and the sign of this distortion does not appear to be unambiguous). Private insurance is sufficient when markets are fair, but it will be replaced by public insurance (public LTC benefits) when there are loading costs.

The paper is organized as follows. In Section 2 we introduce the economic setup. The first-best allocation is described in Section 3 followed by the analysis of the laissez- 
faire allocation (subgame perfect equilibrium of the "aid for bequest" game) in Section 4. Section 5 compares the two outcomes and shows how the first-best allocation can be decentralized. Second-best policies under different informational assumptions are presented in Sections 6 and 7. The former determines the optimal policy instruments when aid is not observable, while the latter for the case where families differ in (unobservable) wealth. Section 8 offers some concluding remarks. More technical material, including all proofs, is relegated to the Appendix.

\section{The model}

Consider a population (which size is normalized to one) consisting of one parent (subscript ' $p$ ') and one child (subscript ' $c$ ') families. While the child is selfish, the parent is a pure altruist. The parent is retired and has accumulated wealth $\omega$. He faces the probability $\pi$ of becoming dependent and needing long-term care. The need of LTC requires expenditures of amount $L$ and comes along with a utility loss due to the deprivation of autonomy captured by $q \leq 0$. LTC insurance coverage can be bought on the private market at a price $p \geq \pi$. For $p=\pi$ LTC insurance is actuarially fair. The parent decides how much LTC insurance coverage $I$ to buy and how much he wants to leave as a bequest to his child. The child decides how much labor to supply and how much informal care to provide. On the one hand, care provided by the child reduces the monetary loss from LTC by $h(a) \leq L$ (with $h^{\prime}>0, h^{\prime \prime}<0$ ) since then the parent requires less professional care services. On the other hand, it reduces the (utility) loss the parent suffers from LTC implying $q^{\prime}(a) \geq 0$ (with $q^{\prime \prime}<0$ ). The latter reflects the fact that the parent prefers care by his child to care provided by a "stranger" or to entering a nursing home. The child, earns income $w \ell$, where $w$ denotes the child's wage rate and $\ell$ labor supply. Labor supply as well as informal care provision come along with disutility captured by $v$, with $v^{\prime}>0, v^{\prime \prime}>0$.

The altruistic parent maximizes the following welfare function

$$
W_{p}=U_{p}+U_{c}
$$

Individual utility of the parent $U_{p}$ is given by

$$
U_{p}=\pi[u(\omega-p I+I-L+h(a)-b)+q(a)]+(1-\pi) u(\omega-p I-\widehat{b}),
$$


where a ${ }^{\wedge}$ indicates the state of staying healthy. Utility of the child is given by

$$
U_{c}=\pi[u(w \ell+b)-v(\ell+a)]+(1-\pi)[u(w \widehat{\ell}+\widehat{b})-v(\widehat{\ell})] .
$$

The utility function satisfies $u^{\prime}>0, u^{\prime \prime}<0$ and $u^{\prime \prime \prime} \geq 0 .{ }^{5}$

The timing of the model is as follows: first the government announces its policy. Then, the parent and the child play the following three stage game. In stage 1 , the parent decides how much LTC insurance coverage, $I$, to buy. In stage 2 , the state of nature is revealed, that is, the parent is either disabled or not. Then, the child decides how much labor to supply, $\ell$ and $\widehat{\ell}$, and how much informal care, $a$, to provide if the parent is dependent. Finally, in stage 3 the parent decides the level of bequests, $b, \widehat{b} \geq 0$, in each state of nature. To determine the subgame perfect Nash equilibrium we solve this game by backward induction. But, before we turn our attention to the laissez-faire we study the first-best allocation which provides a benchmark against which we can compare the laissez-faire allocation.

\section{First-best solution}

With ex ante identical families, we can define the optimal allocation as the one maximizing the expected utility of a representative dynasty. This problem can be written as

$$
\begin{array}{clrl}
\max _{\ell, \widehat{\ell}, a, m_{p}, m_{c}, \widehat{m}_{p}, \widehat{m}_{c}} & W^{f b}=\pi\left[u\left(m_{p}\right)+q(a)+u\left(m_{c}\right)-v(\ell+a)\right] \\
& & +(1-\pi)\left[u\left(\widehat{m}_{p}\right)+u\left(\widehat{m}_{c}\right)-v(\widehat{\ell})\right] \\
\text { s.t. } & \omega+(1-\pi) w \ell+\pi[w \widehat{\ell}+h(a)]=\pi\left[m_{p}+m_{c}+L\right]+(1-\pi)\left[\widehat{m}_{p}+\widehat{m}_{c}\right],
\end{array}
$$

where the decision variables are labor supplies, $\ell$ and $\widehat{\ell}$, informal care, $a$, and consumption levels of the parent and the child in both states of nature. We denote the latter by $m_{p}, m_{c}, \widehat{m}_{p}$ and $\widehat{m}_{c}$. In the first-best all variables are directly set, assuming full information and disregarding the multi-stage structure of the game. However, the specification of the game will of course be relevant below when we study the decentralization of the first-best optimum. Denoting the Lagrange multiplier associated with the resource constraint (1) by $\mu$, the first order conditions (FOCs) characterizing the optimal solution

\footnotetext{
${ }^{5}$ The assumption on the third derivative is not essential for our analysis. It is used for a single result; see Subsection 7.2.
} 
can be written as follows

$$
\begin{aligned}
u^{\prime}\left(m_{p}^{f b}\right)=u^{\prime}\left(m_{c}^{f b}\right) & =u^{\prime}\left(\widehat{m}_{p}^{f b}\right)=u^{\prime}\left(\widehat{m}_{c}^{f b}\right)=\mu, \\
& \frac{v^{\prime}\left(\widehat{\ell}^{f b}\right)}{u^{\prime}\left(\widehat{m}_{c}^{f b}\right)}=w, \\
& \frac{v^{\prime}\left(\ell^{f b}+a^{f b}\right)}{u^{\prime}\left(m_{c}^{f b}\right)}=w, \\
& h^{\prime}\left(a^{f b}\right)+\frac{q^{\prime}\left(a^{f b}\right)}{u^{\prime}\left(m_{c}^{f b}\right)}=w .
\end{aligned}
$$

These expressions are pretty much self-explanatory. Equation (2) states the equality of marginal utilities of incomes across individuals and states of nature (full insurance). Equations (3) and (4) are the usual conditions describing the efficient choice of labor supply. For informal care we obtain a similar condition, except that this variable involves both monetary benefits, $h^{\prime}(a)$, and utility gains, $q^{\prime}(a)$, which translates into the marginal rate of substitution term on the LHS of equation (5).

\section{Laissez-faire allocation}

\subsection{Stage 3: optimal bequests}

The parent is either healthy or dependent. In both states of nature he observes the child's labor income and informal care provision (in case he requires LTC). The parent chooses his optimal bequests by maximizing welfare; equation (6) when he is healthy and equation (7) when he requires LTC:

$$
\begin{aligned}
\max _{\widehat{b}} & \widehat{W}_{p}=u(\omega-p I-\widehat{b})+u(w \widehat{\ell}+\widehat{b})-v(\widehat{\ell}), \\
\max _{b} & W_{p}=u(\omega+(1-p) I-L+h(a)-b)+q(a)+u(w \ell+b)-v(\ell+a) .
\end{aligned}
$$

Assuming an interior solution, the optimal bequests in each state of nature are implicitly given by

$$
\begin{aligned}
& \frac{\partial \widehat{W}_{p}}{\partial \widehat{b}}=-u^{\prime}\left(\widehat{m}_{p}\right)+u^{\prime}\left(\widehat{m}_{c}\right)=0 \\
& \frac{\partial W_{p}}{\partial b}=-u^{\prime}\left(m_{p}\right)+u^{\prime}\left(m_{c}\right)=0 .
\end{aligned}
$$

That is, bequests are chosen so that consumption levels between the parent and the child are equal in both states of nature. Recall that bequests are restricted to be nonnegative, 
and one obtains from (8) and (9)

$$
\begin{aligned}
\widehat{b}>0 & \Longleftrightarrow \omega-p I>w \widehat{\ell}, \\
b>0 & \Longleftrightarrow \omega+(1-p) I-L+h(a)>w \ell .
\end{aligned}
$$

In words, the net resources of the parents (including LTC cost and the monetary value of informal aid, if any) must be larger than that of the children, otherwise the bequest motive is not operative.

Let $\widehat{b}^{*} \equiv \widehat{b}(I, \widehat{\ell})$ and $b^{*} \equiv b(I, \ell, a)$ denote the optimal bequest levels. When the solution is interior, the derivatives with respect to LTC insurance coverage, labor supplies and informal care are as follows

$$
\begin{aligned}
& \frac{\partial b^{*}}{\partial a}=\frac{u^{\prime \prime}\left(m_{p}\right) h^{\prime}(a)}{u^{\prime \prime}\left(m_{p}\right)+u^{\prime \prime}\left(m_{c}\right)}=\frac{h^{\prime}(a)}{2}, \\
& \frac{\partial b^{*}}{\partial \ell}=\frac{-u^{\prime \prime}\left(m_{c}\right) w}{u^{\prime \prime}\left(m_{p}\right)+u^{\prime \prime}\left(m_{c}\right)}=-\frac{w}{2} \equiv \frac{\partial \widehat{b}^{*}}{\partial \widehat{\ell}}, \\
& \frac{\partial b^{*}}{\partial I}=\frac{(1-p) u^{\prime \prime}\left(m_{p}\right)}{u^{\prime \prime}\left(m_{p}\right)+u^{\prime \prime}\left(m_{c}\right)}=\frac{1-p}{2}, \quad \frac{\partial \widehat{b}^{*}}{\partial I}=-\frac{p}{2} .
\end{aligned}
$$

When the child increases his LTC provision the parent increases his bequest by half of the additional return. On the other hand, if the child increases his labor supply and thereby his income, then half of this additional income is taxed away by a reduction in the parent's bequest. The net return (when dependent) and the costs (when healthy) of additional LTC insurance coverage are equally divided between the parent and the child.

\subsection{Stage 2: optimal labor supply and informal care provision}

The child takes into account the bequest he gets from the parent and chooses labor supply and informal care by maximizing

$$
\begin{array}{ll}
\max _{\widehat{\ell}} & \widehat{U}_{c}=u(w \widehat{\ell}+\widehat{b}(I, \widehat{\ell}))-v(\widehat{\ell}), \\
\max _{\ell, a} & U_{c}=u(w \ell+b(I, \ell, a))-v(\ell+a) .
\end{array}
$$


The FOCs with respect to $\widehat{\ell}, \ell$ and $a$ are given by

$$
\begin{aligned}
\frac{\partial \widehat{U}_{c}}{\partial \widehat{\ell}} & =u^{\prime}\left(\widehat{m}_{c}\right)\left(w+\frac{\partial \widehat{b}^{*}}{\partial \widehat{\ell}}\right)-v^{\prime}(\widehat{\ell})=0, \\
\frac{\partial U_{c}}{\partial \ell} & =u^{\prime}\left(m_{c}\right)\left(w+\frac{\partial b^{*}}{\partial \ell}\right)-v^{\prime}(\ell+a)=0, \\
\frac{\partial U_{c}}{\partial a} & =u^{\prime}\left(m_{c}\right) \frac{\partial b^{*}}{\partial a}-v^{\prime}(\ell+a)=0 .
\end{aligned}
$$

Equations (15) and (16) show that the anticipation of a positive bequest reduces the child's marginal benefits of labor supply and the rotten kid becomes the lazy rotten kid. This is because the parent lowers the bequest as child's income increases. In other words, part of the child's extra revenue is "taxed away" by the parents. Equation (17) implies that without a bequest, it is never optimal for the selfish child to provide LTC. If the bequest motive is operative ( $b$ is determined by an interior solution) then the amount bequeathed increases with informal care provision since informal care reduces the monetary costs of LTC; see equation (10).

For an operative bequest motive equations (10) to (12) imply

$$
\begin{aligned}
h^{\prime}(a) & =w, \\
u^{\prime}\left(m_{c}\right) \frac{w}{2} & =v^{\prime}(\ell+a), \\
u^{\prime}\left(\widehat{m}_{c}\right) \frac{w}{2} & =v^{\prime}(\widehat{\ell}) .
\end{aligned}
$$

These expressions implicitly determine labor supply in both states of nature, as functions of $I$ (set in the previous stage of the game): $\ell^{*} \equiv \ell(I)$ and $\widehat{\ell}^{*} \equiv \widehat{\ell}(I)$. Equation (18) specifies informal care $a^{*}$ which is independent of LTC insurance coverage. Since the child acts in a completely selfish way when determining his informal care provision, he only takes into consideration its effect on bequests. Both informal care and labor cause the same disutility. So in the optimum the child equalizes their returns. Recall that $\partial b^{*} / \partial a=h^{\prime}(a) / 2$ which means that the child will receive half of the monetary value his aid represents to the parent. However, since wage income is also "taxed away" at $50 \%$ the tradeoff represented by equation (18) is effectively the efficient one as far the monetary value of aid is concerned. The non-monetary value of aid (that arises when $\left.q^{\prime}(a)>0\right)$ is not taken into account because it does not translate into a higher bequest. Consequently, informal aid is efficient when $q^{\prime}(a)=0$; otherwise it is too low because the utility benefits, $q^{\prime}(a) / u^{\prime}\left(m_{p}\right)$, valued by parents are not accounted for. 
The comparative statics of labor supply with respect to $I$ (under an operative bequest motive) are given by

$$
\begin{aligned}
& \frac{\partial \ell^{*}}{\partial I}=\frac{-u^{\prime \prime}\left(m_{c}\right)\left(w+\frac{\partial b^{*}}{\partial \ell}\right) \frac{\partial b^{*}}{\partial I}}{u^{\prime \prime}\left(m_{c}\right)\left(w+\frac{\partial b^{*}}{\partial \ell}\right)^{2}-v^{\prime \prime}(\ell+a)}=\frac{-u^{\prime \prime}\left(m_{c}\right)(1-p) w}{u^{\prime \prime}\left(m_{c}\right) w^{2}-4 v^{\prime \prime}(\ell+a)}<0, \\
& \frac{\partial \widehat{\ell}^{*}}{\partial I}=\frac{-u^{\prime \prime}\left(\widehat{m}_{c}\right)\left(w+\frac{\partial \widehat{b}^{*}}{\partial \widehat{\ell}}\right) \frac{\partial \widehat{b}^{*}}{\partial I}}{u^{\prime \prime}\left(\widehat{m}_{c}\right)\left(w+\frac{\partial \widehat{b}^{*}}{\partial \widehat{\ell}}\right)^{2}-v^{\prime \prime}(\widehat{\ell})}=\frac{u^{\prime \prime}\left(\widehat{m}_{c}\right) p w}{u^{\prime \prime}\left(\widehat{m}_{c}\right) w^{2}-4 v^{\prime \prime}(\widehat{\ell})}>0 .
\end{aligned}
$$

Since LTC insurance is a net benefit for the parent in the state of dependency it increases the parent's bequest and thereby reduces labor supply incentives of the child. In the state of being healthy, by contrast, LTC insurance is only a cost which in turn reduces the bequest and the child becomes less "lazy".

Finally, when the bequest motive is not operative, we obtain

$$
\begin{aligned}
a & =0, \\
u^{\prime}\left(m_{c}\right) w & =v^{\prime}(\ell+a), \\
u^{\prime}\left(\widehat{m}_{c}\right) w & =v^{\prime}(\widehat{\ell}) .
\end{aligned}
$$

In words, with no bequests there is no aid, but labor supply decisions are efficient (since there is no implicit tax anymore). Interestingly, once the bequest motive becomes operative, the actual level of the bequest is of relevance for the level of labor supply but not for the level of family aid; see equation (18).

\subsection{Stage 1: optimal LTC insurance coverage}

We now turn to the first stage in which the parent chooses LTC insurance coverage $I$ to maximize the following welfare function

$$
\begin{aligned}
\max _{I} W_{p}= & \pi\left[u\left(\omega+(1-p) I-L+h\left(a^{*}\right)-b^{*}\right)+q\left(a^{*}\right)+u\left(w \ell^{*}+b^{*}\right)-v\left(\ell^{*}+a^{*}\right)\right] \\
& +(1-\pi)\left[u\left(\omega-p I-\widehat{b}^{*}\right)+u\left(w \widehat{\ell}^{*}+\widehat{b}^{*}\right)-v\left(\widehat{\ell}^{*}\right)\right]
\end{aligned}
$$

In this function $a^{*}, b^{*}, \ell^{*}, \widehat{b}^{*}$ and $\widehat{\ell^{*}}$ are determined at the equilibrium of the subsequent stages which, as described in the previous subsections, is contingent on the level of $I$ 
set in the first stage. The FOC of (26) with respect to $I$ is given by

$$
\begin{aligned}
\frac{\partial W_{p}}{\partial I} & =\pi u^{\prime}\left(m_{p}\right)\left(1-p-\frac{\partial b^{*}}{\partial I}-\frac{\partial b^{*}}{\partial \ell^{*}} \frac{\partial \ell^{*}}{\partial I}\right)+(1-\pi) u^{\prime}\left(\widehat{m}_{p}\right)\left(-p-\frac{\partial \widehat{b}^{*}}{\partial I}-\frac{\partial \widehat{b}^{*}}{\partial \widehat{\ell}^{*}} \frac{\partial \widehat{\ell}^{*}}{\partial I}\right) \\
& +\pi\left[u^{\prime}\left(m_{c}\right)\left(w \frac{\partial \ell^{*}}{\partial I}+\frac{\partial b^{*}}{\partial I}+\frac{\partial b^{*}}{\partial \ell^{*}} \frac{\partial \ell^{*}}{\partial I}\right)-v^{\prime}\left(\ell^{*}+a^{*}\right) \frac{\partial \ell^{*}}{\partial I}\right] \\
& +(1-\pi)\left[u^{\prime}\left(\widehat{m}_{c}\right)\left(w \frac{\partial \widehat{\ell}^{*}}{\partial I}+\frac{\partial \widehat{b}^{*}}{\partial I}+\frac{\partial \widehat{b}^{*}}{\partial \widehat{\ell}^{*}} \frac{\partial \widehat{\ell}^{*}}{\partial I}\right)-v^{\prime}\left(\widehat{\ell}^{*}\right) \frac{\partial \widehat{\ell}^{*}}{\partial I}\right] .
\end{aligned}
$$

With the envelope theorem, this expression reduces to

$$
\begin{aligned}
\frac{\partial W_{p}}{\partial I}= & \pi u^{\prime}\left(m_{p}\right)\left(1-p-\frac{\partial b^{*}}{\partial \ell^{*}} \frac{\partial \ell^{*}}{\partial I}\right)-(1-\pi) u^{\prime}\left(\widehat{m}_{p}\right)\left(p+\frac{\partial \widehat{b}^{*}}{\partial \widehat{\ell^{*}}} \frac{\partial \widehat{\ell}^{*}}{\partial I}\right)=0 \\
& \Leftrightarrow \frac{u^{\prime}\left(m_{p}\right)}{u^{\prime}\left(\widehat{m}_{p}\right)}=\frac{(1-\pi)\left(p+\frac{\partial \widehat{b}^{*}}{\partial \widehat{\ell}^{*}} \frac{\partial \widehat{\ell}^{*}}{\partial I}\right)}{\pi\left(1-p-\frac{\partial b^{*}}{\partial \ell^{*}} \frac{\partial \ell^{*}}{\partial I}\right)} .
\end{aligned}
$$

Interestingly, equation (28) implies full insurance $\left(m_{p}=\widehat{m}_{p}\right)$ when private insurance is fair $(\pi=p)$. To see this observe that under full insurance (19)-(20) yield $\ell+a=\widehat{\ell}$. It then follows immediately from (11)-(12) together with (21)-(22) that full insurance is a solution to equation (28). This result is not particularly surprising; obtaining full insurance in a fair market is a rather common result (see Mossin, 1968). On the other hand, in our setting it is not obvious at first glance because of the multi-stage nature of the game. Full insurance is only optimal (and for that matter feasible) when the symmetry between states of nature sought in the first stage is not destroyed by the subsequent strategic interactions. This happens to be the case in our setting in particular because total labor supply (market labor plus aid) will be the same in both states of nature.

When $\pi<p$, we obtain $m_{p}<\widehat{m}_{p}$ implying less than full insurance. To see this we take equation (28) and evaluate it at full insurance, that is, $I$ is chosen so that $u^{\prime}\left(\widehat{m}_{p}\right)=u^{\prime}\left(m_{p}\right)$

$$
\left.\frac{\partial W_{p}}{\partial I}\right|_{u^{\prime}\left(m_{p}\right)=u^{\prime}\left(\widehat{m}_{p}\right)}=(\pi-p) u^{\prime}\left(m_{p}\right)\left(1-\frac{u^{\prime \prime}\left(m_{c}\right) w^{2}}{2 u^{\prime \prime}\left(m_{c}\right) w^{2}-8 v^{\prime \prime}(\ell+a)}\right)<0,
$$

which is negative since the first term in brackets is negative for $\pi<p$ and the second term in brackets is positive. In other words, a marginal reduction in $I$, from its full insurance level increases welfare. Consequently, the parents' optimal choice involves lower than full insurance. ${ }^{6}$

\footnotetext{
${ }^{6}$ As long as $W_{p}$ is a concave function of $I$ (and given that in stage 1, the parent's problem is single dimensional).
} 


\section{Laissez-faire versus first-best allocation}

The following proposition summarizes the main results of Sections 3 and 4 and specifically compares the laissez-faire equilibrium to the first-best allocation. ${ }^{7}$

Proposition 1 The laissez-faire solution (subgame perfect equilibrium) of the three stage game with altruistic parents and selfish children has the following properties:

(i) when private insurance is fair, $\pi=p$, there is full insurance, $m_{p}=\widehat{m}_{p}$; otherwise insurance is less than full, $m_{p}<\widehat{m}_{p}$.

(ii) when the bequest motive is operative (so that $b, \widehat{b}>0$ ):

(a) we have $a>0$ and defined by $h^{\prime}(a)=w$. Consequently, informal aid is efficient when $q^{\prime}(a)=0$; otherwise it is too low because the utility benefits, $q^{\prime}(a) / u^{\prime}\left(m_{p}\right)$, valued by parents are not accounted for.

(b) children's market labor supply in both states of nature is inefficient; there is a downward distortion because children face an implicit tax of $50 \%$ on their labor income (via a reduction in bequests).

(iii) when the bequest motive is not operative (so that $b=\widehat{b}=0$ ):

(a) we have $a=0$; no informal aid is provided. Consequently, aid provision is always inefficient.

(b) children's market labor supply decision is efficient in both states of nature; they no longer face any implicit tax on their labor incomes.

\subsection{The case for public LTC policy}

The results summarized in Proposition 1 provide us with a basis on which we can build to assess the opportunity and the design of public LTC policy. The first item suggests that public intervention is useful to overcome inefficiencies in the private insurance market. When, as is typically observed in reality, $p>\pi$ the laissez-faire solution implies insufficient insurance.

Though interesting and realistic, this is not at the heart of our analysis. Our focus will be on the interaction between public policy and family aid. As long as the bequest motive is operative the children do provide some informal aid to their parents, however, its level is too low except when $q^{\prime}(a)=0$ (so that the full impact of aid is captured

\footnotetext{
${ }^{7}$ The comparison follows directly from expression (18)-(20), (23)-(25) and (2)-(3).
} 
by its monetary valuation in the parent's utility). Children's labor supply is then also inefficient, but this problem is not directly connected to the potential need for LTC. When the bequest motive is not operative no family aid will be provided and the case for public intervention will be even stronger. Strikingly, this failure of family aid may effectively be related to private market inefficiencies. To see this assume that $p L>\omega>\pi L$. In that case the individual cannot afford to buy insurance coverage to cover the potential monetary costs of LTC. In case of dependency, the individual will then not only run out of resources, but he can also not count on any family aid (since he has no resources to leave a bequest). However, as long as $\omega>\pi L$ the individual can afford insurance coverage at a fair rate. Interestingly, this may even result in a positive bequest and thus bring about a positive level of aid. To sum up, crowding out of private aid by public LTC is not a problem in this setting. With an operative bequest motive, public LTC will have no impact on private aid. More amazingly, when the bequest motive is (initially) not operative, public LTC insurance may even enhance the provision of informal aid.

Either way, the effectiveness and the design of public LTC depend on the available instruments which are ultimately of course a question of information. In the next section we first study the implementation of the FB under full information. Though of limited realism this is an interesting benchmark to show which instruments are necessary within this setting of multi-stage strategic interactions to obtain the efficient solution. Next, we look at a second-best solution which is achieved when aid is not observable (and thus cannot be subsidized). Finally, we turn to a setting where individuals are heterogenous and dynasties differ in wealth. This adds an extra potential justification for public intervention, namely redistribution. It also makes the case where some individuals cannot afford private LTC coverage more plausible and we can have an initial equilibrium in which the bequest motive is operative for some individuals and not for others.

\subsection{Decentralization of the first-best allocation}

Assume for the time being that there is no asymmetry of information so that all relevant variables including informal aid are publicly observable. The following proposition (which is established in the Appendix 2) shows how this FB allocation within our multi-stage setting can be decentralized by a lump-sum transfer from the healthy to the 
dependent elderly $(\widehat{D}, D)$ supplemented by linear subsidies on labor incomes $\left(\widehat{\tau}_{y}, \tau_{y}\right)$ and aid $\left(\tau_{a}\right)$.

Proposition 2 Under full information, the FB allocation can be decentralized by a lump-sum transfer from the dependent to the healthy elderly supplemented by linear subsidies on labor incomes (of the young) and aid. To achieve this, the instruments are set at the following levels:

(i) the rates of subsidies on $w \ell$ and $w \widehat{\ell}$ denoted $\tau_{y}$ and $\widehat{\tau}_{y}$ are given by

$$
\tau_{y}=\widehat{\tau}_{y}=1
$$

(ii) informal care is subsidized at rate $\tau_{a}$ given by

$$
\tau_{a}=h^{\prime}\left(a^{f b}\right)+2 \frac{q^{\prime}\left(a^{f b}\right)}{u^{\prime}\left(m_{c}^{f b}\right)}
$$

(iii) the lump-sum transfer to dependent elderly, D, and the lump-sum tax imposed on the healthy elderly, $\widehat{D}$, are given by

$$
\begin{aligned}
& D=(1-\pi)\left[L-h\left(a^{f b}\right)\right]-\tau_{a} a^{f b}-\tau_{y} w \ell^{f b}, \\
& \widehat{D}=\pi\left[L-h\left(a^{f b}\right)\right]+\widehat{\tau}_{y} w \widehat{\ell}^{f b} .
\end{aligned}
$$

The intuition behind these conditions is as follows. Condition (29) is the most straightforward: since the children face a $50 \%$ implicit tax on their labor incomes (via the reduction in bequests), we have to subsidize them at rate 1 . In other words, the total income is multiplied by 2 of which the children receive half so that we get the correct tradeoff. Expression (30) is also quite intuitive, except that the factor 2 may appear to be surprising at first. The sole benefit children get from $a$ is $h^{\prime}(a) / 2$; see equation (10). Consequently, the remaining social benefits, namely

$$
\frac{h^{\prime}\left(a^{f b}\right)}{2}+\frac{q^{\prime}\left(a^{f b}\right)}{u^{\prime}\left(m_{c}^{f b}\right)},
$$

are not taken into account. This can be compensated by a subsidy. However since half of the subsidy will be lost due to the reduction in bequests, $\tau_{a}$ must be set at a level of twice the unaccounted social benefits, which yields (30).

Turning to $D$ and $\widehat{D}$, the dependent old get the monetary loss of dependency (which is exactly the net benefit a fair private insurance would give) less the subsidies to their children. In sum, since parents finance the subsidies to their own children, these 
payments do not involve any transfers between families (that is across states of nature). Such transfers are not necessary because the lump sum transfers between the elderly are already designed to achieve full insurance.

This first-best decentralization provides an interesting benchmark. However, in reality some of the relevant variables are likely not to be publicly observable which, in turn, will restrict the available policy instruments. We shall now study the policy design in second-best settings where information is no longer complete. We start by a setting in which informal aid is not observable so that it cannot be subsidized.

\section{Second-best: unobservable aid}

Assume the government employs a lump-sum tax on the healthy old, $\widehat{D}$ and taxes child's income at a proportional rate $t$ when parents are dependent and at a rate $\widehat{t}$ when they are healthy to finance public LTC provision, $D$ to dependent parents. ${ }^{8}$ The optimization problem is then characterized by

$$
\begin{aligned}
& \max _{t, \widehat{t}, D, \widehat{D}} W(t, \widehat{t}, D, \widehat{D})=\left.\pi u\left(\omega+(1-p) I^{*}+D-L+h\left(a^{*}\right)-b^{*}\right)+q\left(a^{*}\right)\right] \\
&+\pi\left[u\left((1-t) w \ell^{*}+b^{*}\right)-v\left(\ell^{*}+a^{*}\right)\right] \\
&+(1-\pi)\left[u\left(\omega-p I^{*}-\widehat{D}-\widehat{b}^{*}\right)+u\left((1-\widehat{t}) w \widehat{\ell}^{*}+\widehat{b}^{*}\right)-v\left(\widehat{\ell}^{*}\right)\right] \\
& \text { s.t. } \quad \pi t w \ell^{*}+(1-\pi) \widehat{t} w \widehat{\ell}^{*}+(1-\pi) \widehat{D}=\pi D .
\end{aligned}
$$

The FOCs of the above problem with respect to $t, \widehat{t}, D$ and $\widehat{D}$ are given by

$$
\begin{aligned}
\frac{\partial \mathcal{L}}{\partial t}= & u^{\prime}\left(m_{p}\right)\left(h^{\prime}\left(a^{*}\right) \frac{\partial a^{*}}{\partial t}-\frac{\partial b^{*}}{\partial \ell^{*}} \frac{\partial \ell^{*}}{\partial t}-\frac{\partial b^{*}}{\partial a^{*}} \frac{\partial a^{*}}{\partial t}\right)+q^{\prime}\left(a^{*}\right) \frac{\partial a^{*}}{\partial t} \\
& -u^{\prime}\left(m_{c}\right) w \ell^{*}+\mu\left(w \ell^{*}+t w \frac{\partial \ell^{*}}{\partial t}\right)=0 \\
\frac{\partial \mathcal{L}}{\partial \widehat{t}}= & -u^{\prime}\left(\widehat{m}_{p}\right) \frac{\partial \widehat{b}^{*}}{\partial \widehat{\ell}^{*}} \frac{\partial \widehat{\ell}^{*}}{\partial \widehat{t}}-u^{\prime}\left(\widehat{m}_{c}\right) w \widehat{\ell^{*}}+\mu\left(w \widehat{\ell^{*}}+\widehat{t w} \frac{\partial \widehat{\ell}^{*}}{\partial t}\right)=0 \\
\frac{\partial \mathcal{L}}{\partial D}= & u^{\prime}\left(m_{p}\right)\left(1-\frac{\partial b^{*}}{\partial \ell^{*}} \frac{\partial \ell^{*}}{\partial D}\right)-\mu\left(1-t w \frac{\partial \ell^{*}}{\partial D}\right)=0 \\
\frac{\partial \mathcal{L}}{\partial \widehat{D}}= & -u^{\prime}\left(\widehat{m}_{p}\right)\left(1+\frac{\partial \widehat{b}^{*}}{\partial \widehat{\ell}^{*}} \frac{\partial \widehat{\ell^{*}}}{\partial \widehat{D}}\right)+\mu\left(1+\widehat{t w} \frac{\partial \widehat{\ell}^{*}}{\partial \widehat{D}}\right)=0 .
\end{aligned}
$$

\footnotetext{
${ }^{8} \mathrm{~A}$ change in the distribution of income between families does not alter their consumption as long as the parent is an effective altruist. In other words, whether the lump sum transfer is payed by the children or by the parent is irrelevant. This neutrality property is the basis of the Ricardian equivalence (see Barro, 1974).
} 
Appendix B shows that rearranging and combining these FOCs and defining the compensated effects as follows ${ }^{9}$

$$
\begin{aligned}
& \frac{\partial \ell^{* c}}{\partial t}=\frac{\partial \ell^{*}}{\partial t}+w \ell^{*} \frac{\partial \ell^{*}}{\partial D}, \\
& \frac{\partial \widehat{\ell}^{* c}}{\partial \widehat{t}}=\frac{\partial \widehat{\ell}^{*}}{\partial \widehat{t}}-w \widehat{\ell}^{*} \frac{\partial \widehat{\ell}^{*}}{\partial \widehat{D}}
\end{aligned}
$$

yields the following proposition.

Proposition 3 Assume that informal aid, a, is not observable and that policy instruments are restricted to public LTC provision to dependent parents, D, financed by a lump-sum tax on the healthy old, $\widehat{D}$, and a linear tax on the children's labor income at rates $t$ and $\widehat{t}$. The optimal policy is characterized by:

(i) $u^{\prime}\left(\widehat{m}_{p}\right)=u^{\prime}\left(m_{p}\right)$ : the transfers are used to achieve full insurance which (for an operative bequest motive) also implies full insurance for the children, $u^{\prime}\left(\widehat{m}_{c}\right)=u^{\prime}\left(m_{c}\right)$.

(ii) the following optimal tax rates in the dependent and healthy state

$$
\begin{aligned}
& t=\frac{\left[h^{\prime}\left(a^{*}\right)+\frac{q^{\prime}\left(a^{*}\right)}{u^{\prime}\left(m_{p}\right)}\right] \frac{\partial a^{*}}{\partial t}-\left[\frac{\partial b^{*}}{\partial \ell^{*}} \frac{\partial \ell^{* c}}{\partial t}+\frac{\partial b^{*}}{\partial a^{*}} \frac{\partial a^{*}}{\partial t}\right]}{-w \frac{\partial \ell^{* c}}{\partial t}}, \\
& \widehat{t}=-1 .
\end{aligned}
$$

To explain these results let us first interpret the expression for $t$; equation (40). The numerator can be interpreted as Pigouvian terms. The first one is a direct effect which resembles the Pigouvian expression derived in the previous section. The child does not consider the positive externality of informal care provision on the parent's utility. This calls for a positive income tax which is effectively a subsidy on aid. However, the labor and aid variations induced by the tax also have indirect effects on the parent's utility. These effects are negative and operate via the adjustment in bequests. Both more aid and lower labor supply increase bequests and thus reduce parent's utility, which counteracts the first positive effect of higher income taxes. The denominator represents the deadweight loss of income taxation. Finally, the optimal tax rate in the healthy state, $\widehat{t}$, simply reflects the first-best subsidy on labor which is equal to one.

To sum up, transfers are used to achieve full insurance of the old. The tax on labor, on the other hand, is not used to raise revenue but because it increases informal aid

\footnotetext{
${ }^{9}$ The sign of the last term changes because one is a transfer and the other a tax, so the compensation (to remain at the same utility level) goes in opposite directions. We expect these compensated effects to be negative.
} 
(which becomes more attractive when market labor is taxed). The level of $t$ is then set to strike a balance between the deadweight loss of the labor tax (the denominator of (40)) against the net benefits associated with its effect on aid (which arise provided that the direct effects in the numerator (40) dominate the negative ones), while $\widehat{t}$ is at its first-best level.

\section{Heterogenous families}

So far, families were identical. In this section we introduce parents who differ in their wealth $\omega_{i}(i=l, h)$ where $\omega_{l}<\omega_{h}$. This brings in another important justification for government intervention, namely redistribution. It also makes the case where some parents cannot afford private LTC coverage more plausible, and we can have an initial equilibrium in which the bequest motive is operative for some families and not for others. The share of type- $i$ families is given by $\phi_{i}$. We assume that $\omega_{i}$ is unobservable to the government. To concentrate on the implications of wealth heterogeneity we assume that all other variables, that is, bequests $\left(b_{i}, \widehat{b}_{i}\right)$, labor supplies $\left(\ell_{i}, \widehat{\ell}_{i}\right)$, informal care $a_{i}$ and LTC care insurance coverage $I_{i}$ can be observed. The children's consumption levels are thus effectively known by the government. Under the considered information structure instruments include a (possibly nonlinear) transfer scheme for parents and children in each state of nature given by $D\left(I_{i}, b_{i}\right), \widehat{D}\left(I_{i}, \widehat{b}_{i}\right)$ and $T\left(w \ell_{i}, a_{i}\right), \widehat{T}\left(w \widehat{\ell}_{i}\right)$ respectively. In other words, long-term care insurance coverage, bequests, labor supply and aid can be taxed or subsidized and $D_{i}, \widehat{D}_{i}$ and $T_{i}, \widehat{T}_{i}$ can be positive or negative.

With wealth heterogeneity, the (utilitarian) first-best allocation continues to be defined by expressions (2)-(5) which apply for all types. The full information implementation of the first-best allocation remains as described in Proposition 2 except that the transfers $D$ and $\widehat{D}$ are now type specific and designed to eliminate wealth differences. ${ }^{10}$ Consequently, they imply a transfer from high- to low-wealth families. In a second-best world with unobservable wealth and a utilitarian welfare function, the incentive constraint from type- $h$ to type- $l$ families will then be binding.

We proceed as follows: first, we reconsider the various states of the "aid for bequest" game with nonlinear taxes and transfers and in particular parent's and child's optimiza-

\footnotetext{
${ }^{10}$ All the other expressions in the proposition continue to apply and the taxes and subsidies on $\ell, \widehat{\ell}$ and $a$ are the same for all types.
} 
tion. Then, we determine the second-best allocation and show how the transfer scheme must be designed to implement this allocation.

\subsection{Equilibrium with nonlinear taxes and transfers}

Given the above described transfer scheme, parent's and child's utilities are given by ${ }^{11}$

$$
\begin{aligned}
W_{p}^{i}= & \pi\left[u\left(\omega_{i}+(1-p) I_{i}-L+h\left(a_{i}\right)-b_{i}+D\left(I_{i}, b_{i}\right)\right)+q\left(a_{i}\right)\right] \\
& +(1-\pi) u\left(\omega_{i}-p I_{i}-\widehat{b}_{i}+\widehat{D}\left(I_{i}, \widehat{b}_{i}\right)\right)+U_{c}^{i} \\
U_{c}^{i}= & \pi\left[u\left(w \ell_{i}+b_{i}+T\left(w \ell_{i}, a_{i}\right)\right)-v\left(\ell_{i}+a_{i}\right)\right] \\
& +(1-\pi)\left[u\left(w \widehat{\ell}_{i}+\widehat{b}_{i}+\widehat{T}\left(w \widehat{\ell}_{i}\right)\right)-v\left(\widehat{\ell}_{i}\right)\right]
\end{aligned}
$$

In stage 3 parents maximize (42) with respect to bequests in both states of nature, $b$ and $\widehat{b}$, which are then implicitly given by

$$
\begin{aligned}
& \frac{u^{\prime}\left(m_{p}^{i}\right)}{u^{\prime}\left(m_{c}^{i}\right)}=\frac{1}{1-D_{b}^{i}}, \\
& \frac{u^{\prime}\left(\widehat{m}_{p}^{i}\right)}{u^{\prime}\left(\widehat{m}_{c}^{i}\right)}=\frac{1}{1-\widehat{D}_{\widehat{b}}^{i}} .
\end{aligned}
$$

$D_{b}^{i}$ and $D_{\widehat{b}}^{i}$ denote partial derivatives which represent marginal tax (or subsidy) rates on bequests. When bequests are taxed (subsidized) $D_{b}^{i}, D_{\widehat{b}}^{i}<(>) 0$, parents have a higher (lower) level of consumption than their children. From the above equations we can calculate the following comparative statics

$$
\begin{aligned}
\frac{\partial b_{i}}{\partial a_{i}} & =\frac{\left(1-D_{b}^{i}\right) u^{\prime \prime}\left(m_{p}^{i}\right) h^{\prime}\left(a_{i}\right)-u^{\prime \prime}\left(m_{c}^{i}\right) T_{a}^{i}}{u^{\prime \prime}\left(m_{c}^{i}\right)+\left(1-D_{b}^{i}\right) u^{\prime \prime}\left(m_{p}^{i}\right)} \\
\frac{\partial b_{i}}{\partial \ell_{i}} & =\frac{-u^{\prime \prime}\left(m_{c}^{i}\right)\left(1+T_{\ell}^{i}\right) w}{u^{\prime \prime}\left(m_{c}^{i}\right)+\left(1-D_{b}^{i}\right) u^{\prime \prime}\left(m_{p}^{i}\right)} \\
\frac{\partial \widehat{b}_{i}}{\partial \widehat{\ell}_{i}} & =\frac{-u^{\prime \prime}\left(\widehat{m}_{c}^{i}\right)\left(1+\widehat{T}_{\widehat{\ell}}^{i}\right) w}{u^{\prime \prime}\left(\widehat{m}_{c}^{i}\right)+\left(1-\widehat{D}_{\widehat{b}}^{i}\right) u^{\prime \prime}\left(\widehat{m}_{p}^{i}\right)} .
\end{aligned}
$$

In the second stage the children choose labor supplies, $\ell_{i}$ and $\widehat{\ell}_{i}$, and informal care provision, $a_{i}$, again taking into consideration their effects on bequests. The marginal

\footnotetext{
${ }^{11}$ Type indices are generally subscripts but they become superscripts when either the subscript is already used to indicate the family member, i.e. the child or the parent, or when the subscript is already used for a partial derivative. This is simply to avoid multiple subscripts.
} 
rates of substitution are as follows

$$
\begin{aligned}
\frac{v^{\prime}\left(\ell_{i}+a_{i}\right)}{u^{\prime}\left(m_{c}^{i}\right)} & =\left(1+T_{\ell}^{i}\right) w+\frac{\partial b_{i}}{\partial \ell_{i}}=\left[1-\frac{u^{\prime \prime}\left(m_{c}^{i}\right)}{u^{\prime \prime}\left(m_{c}^{i}\right)+\left(1-D_{b}^{i}\right) u^{\prime \prime}\left(m_{p}^{i}\right)}\right]\left(1+T_{\ell}^{i}\right) w, \\
\frac{v^{\prime}\left(\ell_{i}+a_{i}\right)}{u^{\prime}\left(m_{c}^{i}\right)} & =T_{a}^{i}+\frac{\partial b_{i}}{\partial a_{i}}=T_{a}^{i}+\frac{\left(1-D_{b}^{i}\right) u^{\prime \prime}\left(m_{p}^{i}\right) h^{\prime}\left(a_{i}\right)-u^{\prime \prime}\left(m_{c}^{i}\right) T_{a}^{i}}{u^{\prime \prime}\left(m_{c}^{i}\right)+\left(1-D_{b}^{i}\right) u^{\prime \prime}\left(m_{p}^{i}\right)} \\
\frac{v^{\prime}\left(\widehat{\ell}_{i}\right)}{u^{\prime}\left(\widehat{m}_{c}^{i}\right)} & =\left(1+\widehat{T}_{\widehat{\ell}}^{i}\right) w+\frac{\partial \widehat{b}_{i}}{\partial \widehat{\ell}_{i}}=\left[1-\frac{u^{\prime \prime}\left(\widehat{m}_{c}^{i}\right)}{u^{\prime \prime}\left(\widehat{m}_{c}^{i}\right)+\left(1-\widehat{D}_{\widehat{b}}^{i}\right) u^{\prime \prime}\left(\widehat{m}_{p}^{i}\right)}\right]\left(1-\widehat{T}_{\widehat{\ell}}^{i}\right) w .
\end{aligned}
$$

In the first stage, parents choose their private insurance protection, I. However, since we show below that private insurance is not necessary to implement the secondbest allocation, we do not reconsider the private insurance decision at this point.

\subsection{Second-best solution}

\subsubsection{The problem}

This subsection characterizes the optimal utilitarian allocation constrained by the information structure just sketched. The optimization problem of the government is given by $^{12}$

$$
\begin{aligned}
\max _{I_{i}, D_{i}, b_{i}, a_{i}, \ell_{i}, T_{i}, \widehat{D}_{i}, \widehat{b}_{i}, \widehat{\ell}_{i}, \widehat{T}_{i}} \quad W & =\sum_{i \in\{l, h\}} \phi_{i}\left\{\pi\left[u\left(w \ell_{i}+b_{i}+T_{i}\right)-v\left(\ell_{i}+a_{i}\right)\right]\right. \\
& +\pi\left[u\left(\omega_{i}+(1-p) I_{i}+D_{i}-L+h\left(a_{i}\right)-b_{i}\right)+q\left(a_{i}\right)\right] \\
& \left.+(1-\pi)\left[u\left(\omega_{i}+\widehat{D}_{i}-p I_{i}-\widehat{b}_{i}\right)+u\left(w \widehat{\ell}_{i}+\widehat{b}_{i}+\widehat{T}_{i}\right)-v\left(\widehat{\ell}_{i}\right)\right]\right\}
\end{aligned}
$$

subject to the resource constraint

$$
\sum_{i \in\{l, h\}} \phi_{i}\left\{\pi\left[D_{i}+T_{i}\right]+(1-\pi)\left[\widehat{D}_{i}+\widehat{T}_{i}\right]\right\}=0
$$

and subject to the following incentive constraints for $i, j \in\{l, h\}$

$$
\begin{aligned}
& \pi\left[u\left(\omega_{i}+(1-p) I_{i}+D_{i}-L+h\left(a_{i}\right)-b_{i}\right)+q\left(a_{i}\right)+u\left(w \ell_{i}+b_{i}+T_{i}\right)-v\left(\ell_{i}+a_{i}\right)\right] \\
& +(1-\pi)\left[u\left(\omega_{i}+\widehat{D}_{i}-p I_{i}-\widehat{b}_{i}\right)+u\left(w \widehat{\ell}_{i}+\widehat{b}_{i}+\widehat{T}_{i}\right)-v\left(\widehat{\ell}_{i}\right)\right] \geq \\
& \pi\left[u\left(\omega_{i}+(1-p) I_{j}+D_{j}-L+h\left(a_{j}\right)-b_{j}\right)+q\left(a_{j}\right)+u\left(w \ell_{j}+b_{j}+T_{j}\right)-v\left(\ell_{j}+a_{j}\right)\right] \\
& +(1-\pi)\left[u\left(\omega_{i}+\widehat{D}_{j}-p I_{j}-\widehat{b}_{j}\right)+u\left(w \widehat{\ell}_{j}+\widehat{b}_{j}+\widehat{T}_{j}\right)-v\left(\widehat{\ell}_{j}\right)\right] \quad \forall i \neq j .
\end{aligned}
$$

This problem characterizes the best allocation (in terms of utilitarian welfare) that can be achieved given the information structure. Observe that since all children have

\footnotetext{
${ }^{12}$ We assume that the solution implies a strictly positive level of aid and thus an operative bequest motive for all types.
} 
the same wage rate their labor supplies, $\ell$ and $\widehat{\ell}$, are effectively observable so that the children of the mimicking parents must have the same labor supplies (and level of $a$ ) as those of the mimicked parents; this explains the writing of the incentive constraint. As usual in models with discrete types (and particularly with only two types) the solution can be implemented in many ways. ${ }^{13}$ In the remainder of this section we shall look at the implementation which interferes as little as possible with the structure of our multi-stage "aid for bequest" game. In other words, we will set the marginal tax rates (whenever possible) so that both children and parents choose the optimal allocation as interior solution of their optimization problem in the relevant stage of the game. We shall first examine the taxation of bequest, and then turn to the labor supply and aid decisions and determine if and how they are distorted and whether they are subject to taxation or subsidization. Finally, we consider private insurance as well as the lumpsum transfers (or taxes) between the elderly $(D$ and $\widehat{D})$ which can be seen as public LTC insurance (or benefits) scheme.

Denote $\lambda_{i j}, i, j \in\{l, h\}$, the Lagrange multiplier associated with the self-selection constraint from type- $i$ to type- $j$ families and $\mu$ the one associated with the resource constraint. The FOCs of this problem are stated in Appendix C. While our formal conditions make no assumption as to the binding incentive constraint, our interpretations below will concentrate on the case where only the downward incentive constraint is binding $\left(\lambda_{h l}>0\right.$ and $\left.\lambda_{l h}=0\right)$. This is the relevant case with a utilitarian social welfare function (which implies redistribution from the high-wealth to the low-wealth individuals).

\subsubsection{Taxation of bequests}

Rearranging the FOCs with respect to $b_{i}$ and $\widehat{b}_{i}$ yields the following marginal rates of substitution between parent's and child's utility

$$
\begin{array}{ll}
\frac{u^{\prime}\left(m_{p}^{i}\right)}{u^{\prime}\left(m_{c}^{i}\right)}=\frac{\phi_{i}+\lambda_{i j}-\lambda_{j i} \frac{u^{\prime}\left(m_{c}^{j i}\right)}{u^{\prime}\left(m_{c}^{i}\right)}\left[1-\frac{u^{\prime}\left(m_{p}^{j i}\right)}{\left.u^{\prime}\left(m_{c}^{j i}\right)\right]}\right.}{\phi_{i}+\lambda_{i j}} \quad \forall i, \\
\frac{u^{\prime}\left(\widehat{m}_{p}^{i}\right)}{u^{\prime}\left(\widehat{m}_{c}^{i}\right)}=\frac{\phi_{i}+\lambda_{i j}-\lambda_{j i} \frac{u^{\prime}\left(\widehat{m}_{c}^{j i}\right)}{u^{\prime}\left(\widehat{m}_{c}^{i}\right)}\left[1-\frac{u^{\prime}\left(\widehat{m}_{p}^{j i}\right)}{u^{\prime}\left(\widehat{m}_{c}^{j i}\right)}\right]}{\phi_{i}+\lambda_{i j}} \quad \forall i .
\end{array}
$$

\footnotetext{
${ }^{13}$ And the nonlinear functions considered above can simply be used to control quantities by assigning large penalties to any choices different from the optimal allocation. Though extreme, this shows that implementation is always possible.
} 
Consider the "top" family, that is, the high-wealth family who is not mimicked implying $\lambda_{l h}=0$. For such a family equations (53) and (54) are equal to one. In other words, rich families' bequests are not taxed at the margin which is the traditional "no distortion at the top" result. With (44) and (45) we thus have $D_{b}^{h}=\widehat{D}_{\widehat{b}}^{h}=0$. Low-wealth families, by contrast, are those who are mimicked by high-wealth families implying $\lambda_{h l}>0$. Since the child's consumption level is effectively observed, we have $u^{\prime}\left(m_{c}^{j i}\right)=u^{\prime}\left(m_{c}^{i}\right)$ and $u^{\prime}\left(\widehat{m}_{c}^{j i}\right)=u^{\prime}\left(\widehat{m}_{c}^{i}\right)$. Rich families who mimic poor families, however, no longer equalize consumption levels between parents and children, but $u^{\prime}\left(m_{p}^{j i}\right)<u^{\prime}\left(m_{c}^{j i}\right)$ and $u^{\prime}\left(\widehat{m}_{p}^{j i}\right)<u^{\prime}\left(\widehat{m}_{c}^{j i}\right)$ due to the parents' higher wealth. With (44) and (45), we have

$$
\begin{aligned}
& \frac{1}{1-D_{b}^{l}}=\frac{\phi_{l}-\lambda_{h l}\left[1-\frac{u^{\prime}\left(m_{p}^{h l}\right)}{u^{\prime}\left(m_{c}^{h l}\right)}\right]}{\phi_{l}}<1, \\
& \frac{1}{1-\widehat{D}_{\widehat{b}}^{l}}=\frac{\phi_{l}-\lambda_{h l}\left[1-\frac{u^{\prime}\left(\widehat{m}_{p}^{h l}\right)}{u^{\prime}\left(\widehat{m}_{c}^{h l}\right)}\right]}{\phi_{l}}<1,
\end{aligned}
$$

implying $D_{b}^{l}, \widehat{D}_{\widehat{b}}^{l}<0$. In other words, poor families face a downward distortion on their bequests. A tax on their bequests relaxes a binding incentive constraint; since type- $h$ families want to bequeath more to their children due to their higher wealth, they are also hurt more by a tax on these transfers.

\subsubsection{Taxation of children's labor supply and aid}

Rearranging the FOCs with respect to $\ell_{i}$ and $\widehat{\ell}_{i}$, we get the following marginal rates of substitution for labor supply in the the dependent and the healthy state respectively

$$
\begin{array}{cc}
\frac{v^{\prime}\left(\ell_{i}+a_{i}\right)}{u^{\prime}\left(m_{c}^{i}\right)}=\frac{\left[\phi_{i}+\lambda_{i j}-\lambda_{j i} \frac{u^{\prime}\left(m_{c}^{j i}\right)}{u^{\prime}\left(m_{c}^{i}\right)}\right] w}{\phi_{i}+\lambda_{i j}-\lambda_{j i}}=w & \forall i, \\
\frac{v^{\prime}\left(\widehat{\ell}_{i}\right)}{u^{\prime}\left(\widehat{m}_{c}^{i}\right)}=\frac{\left[\phi_{i}+\lambda_{i j}-\lambda_{j i} \frac{u^{\prime}\left(\widehat{m}_{c}^{j i}\right)}{u^{\prime}\left(\widehat{m}_{c}^{i}\right)}\right] w}{\phi_{i}+\lambda_{i j}-\lambda_{j i}}=w & \forall i .
\end{array}
$$

Since consumption levels of the children are effectively observed in both states of nature, the tradeoff that both rich and poor families face in the second-best is the same as in the first-best; see equations (3) and (4). Given the multi-stage nature of our problem this however does not imply a marginal tax rate equal to zero. Combining equation 
(49) with (57) and equation (51) with (58), we obtain

$$
\begin{aligned}
& \left(1+T_{\ell}^{i}\right) w+\frac{\partial b_{i}}{\partial \ell_{i}}=\left[1-\frac{u^{\prime \prime}\left(m_{c}^{i}\right)}{u^{\prime \prime}\left(m_{c}^{i}\right)+\left(1-D_{b}^{i}\right) u^{\prime \prime}\left(m_{p}^{i}\right)}\right]\left(1+T_{\ell}^{i}\right) w=w \quad \forall i, \\
& \left(1+\widehat{T}_{\widehat{\ell}}^{i}\right) w+\frac{\partial \widehat{b}_{i}}{\partial \widehat{\ell}_{i}}=\left[1-\frac{u^{\prime \prime}\left(\widehat{m}_{c}^{i}\right)}{u^{\prime \prime}\left(\widehat{m}_{c}^{i}\right)+\left(1-\widehat{D}_{\widehat{b}}^{i}\right) u^{\prime \prime}\left(\widehat{m}_{p}^{i}\right)}\right]\left(1-\widehat{T}_{\widehat{\ell}}^{i}\right) w=w \quad \forall i .
\end{aligned}
$$

That is, the tax on labor is chosen to offset the downward distortion of bequests on labor supply. Solving equations (59) and (60) for $T_{\ell}^{i}$ and $\widehat{T}_{\widehat{\ell}}^{i}$ yields

$$
\begin{aligned}
& T_{\ell}^{i}=\frac{u^{\prime \prime}\left(m_{c}^{i}\right)}{\left(1-D_{b}^{i}\right) u^{\prime \prime}\left(m_{p}^{i}\right)} \quad \forall i, \\
& T_{\widehat{\ell}}^{i}=\frac{u^{\prime \prime}\left(\widehat{m}_{c}^{i}\right)}{\left(1-D_{\widehat{b}}^{i}\right) u^{\prime \prime}\left(\widehat{m}_{p}^{i}\right)} \quad \forall i .
\end{aligned}
$$

Since the rich face no distortion on bequests $\left(D_{b}^{h}=D_{\widehat{b}}^{h}=0\right.$ so that $u^{\prime \prime}\left(m_{c}^{h}\right)=u^{\prime \prime}\left(m_{p}^{h}\right)$ and $\left.u^{\prime \prime}\left(\widehat{m}_{c}^{h}\right)=u^{\prime \prime}\left(\widehat{m}_{p}^{h}\right)\right)$ these expressions imply the first-best marginal tax (subsidy) rates on labor supply: $T_{\ell}^{h}=\widehat{T}_{\widehat{\ell}}^{h}=1$ (see Proposition 2 ). For the poor, by contrast, we have a positive tax rate on bequests, and with our assumptions on utility this implies $u^{\prime \prime}\left(m_{p}^{l}\right) \geq u^{\prime \prime}\left(m_{c}^{l}\right)$ and $u^{\prime \prime}\left(\widehat{m}_{p}^{l}\right) \geq u^{\prime \prime}\left(\widehat{m}_{c}^{l}\right) .{ }^{14}$ In other words, the optimal subsidies on labor supplies for the poor are smaller than the first-best levels. This is quite intuitive. Recall that poor families face a tax on their bequest, which mitigates the negative impact bequests have on labor supply. Because of the bequest tax, an increase in the child's labor income induces a smaller reduction in net bequests than in the absence of (bequest) taxation. Put differently, it alleviates the lazy rotten kid phenomenon. Consequently, labor supplies need to be subsidized at a lower rate to reach the first-best tradeoff.

Let us consider the marginal rate of substitution for informal care provision which can be written as

$$
\frac{v^{\prime}\left(\ell_{i}+a_{i}\right)}{u^{\prime}\left(m_{c}^{i}\right)}=\frac{\left[\phi_{i}+\lambda_{i j}-\lambda i \frac{u^{\prime}\left(m_{c}^{j i}\right)}{u^{\prime}\left(m_{c}^{i}\right)}\right] h^{\prime}\left(a_{i}\right)}{\phi_{i}+\lambda_{i j}-\lambda_{j i}}+\frac{q^{\prime}\left(a_{i}\right)}{u^{\prime}\left(m_{c}^{i}\right)}=h^{\prime}\left(a_{i}\right)+\frac{q^{\prime}\left(a_{i}\right)}{u^{\prime}\left(m_{c}^{i}\right)} \quad \forall i .
$$

As for labor supply, the tradeoff for informal care provision in the second-best is the same as in the first-best. But, again this does not imply zero marginal tax rates. From equation (50), we get

$$
T_{a}^{i}+\frac{\partial b_{i}}{\partial a_{i}}=T_{a}^{i}+\frac{\left(1-D_{b}^{i}\right) u^{\prime \prime}\left(m_{p}^{i}\right) h^{\prime}\left(a_{i}\right)-u^{\prime \prime}\left(m_{c}^{i}\right) T_{a}^{i}}{u^{\prime \prime}\left(m_{c}^{i}\right)+\left(1-D_{b}^{i}\right) u^{\prime \prime}\left(m_{p}^{i}\right)}=h^{\prime}\left(a_{i}\right)+\frac{q^{\prime}\left(a_{i}\right)}{u^{\prime}\left(m_{c}^{i}\right)} \quad \forall i .
$$

\footnotetext{
${ }^{14}$ This result makes use of our assumption that $u^{\prime \prime \prime} \geq 0$.
} 
Informal care provision in the laissez-faire is inefficiently low and to achieve the firstbest tradeoff, it must be subsidized at the margin (see Proposition 2). Solving equation (63) for $T_{a}^{i}$ yields

$$
T_{a}^{i}=\frac{u^{\prime \prime}\left(m_{c}^{i}\right)}{\left(1-D_{b}^{i}\right) u^{\prime \prime}\left(m_{p}^{i}\right)} h^{\prime}\left(a_{i}\right)+\left[\frac{u^{\prime \prime}\left(m_{c}^{i}\right)}{\left(1-D_{b}^{i}\right) u^{\prime \prime}\left(m_{p}^{i}\right)}+1\right] \frac{q^{\prime}\left(a_{i}\right)}{u^{\prime}\left(m_{c}^{i}\right)}>0 \quad \forall i .
$$

Since rich families face no distortion on bequests, the subsidy on aid is again the firstbest one,

$$
T_{a}^{h}=h^{\prime}\left(a_{h}\right)+2 \frac{q^{\prime}\left(a_{h}\right)}{u^{\prime}\left(m_{c}^{h}\right)} .
$$

Poor families, by contrast, face a distortion on their bequests $\left(D_{b}^{l}>0\right)$ and to achieve the first-best tradeoff for informal care, their subsidy on aid is lower. The reason behind this result is that the child equalizes the return of labor with the return of aid. Since the poor's labor supply is already subsidized at a lower than first-best rate, informal care must also be subsidized at a lower rate to obtain the first-best tradeoff for both variables.

\subsubsection{Private insurance and lump-sum transfers}

We now turn to private insurance and public LTC benefits. Before worrying about a possible taxation or subsidization of private insurance, we have to examine whether it is used at all in the second-best. To study this we use the FOCs given in Appendix C. Substituting equations (84) and (85) into equation (78) yields

$$
\begin{aligned}
\frac{\partial \mathcal{L}}{\partial I_{i}}= & \pi(1-p)\left[\lambda_{j i} u^{\prime}\left(m_{p}^{j i}\right)+\mu \phi_{i}\right]-(1-\pi) p\left[\lambda_{j i} u^{\prime}\left(\widehat{m}_{p}^{j i}\right)+\mu \phi_{i}\right] \\
& -\lambda_{j i}\left[\pi(1-p) u^{\prime}\left(m_{p}^{j i}\right)-(1-\pi) p u^{\prime}\left(\widehat{m}_{p}^{j i}\right)\right]=\pi(1-p)-(1-\pi) p \leq 0 .
\end{aligned}
$$

That is, when private insurance is offered at higher than fair rates $(\pi<p)$, it is not used in the second-best solution implying $I_{i}=0$ for $i=l, h$. In other words, private insurance is dominated by "public insurance" provided through transfers and taxes $D_{i}$ and $\widehat{D}_{i}$. With our nonlinear tax scheme, there is no "cost of public funds" (or deadweight loss) so that the public sector can always offer full insurance at fair rates. As we shall now show, this is not necessarily the optimal policy, but the argument shows that private insurance is a dominated instrument, unless it is fair $(\pi=p)$ in which case it does no harm but cannot perform better than public coverage either.

Lets turn our attention to the optimal lump-sum transfers which provide insurance and redistribute from high- to low-wealth families. Note that $D$ can also be interpreted 
as public LTC provision. Rearranging and combining the FOCs with respect to $D_{i}$ and $\widehat{D}_{i}$, we obtain

$$
\frac{u^{\prime}\left(\widehat{m}_{p}^{i}\right)}{u^{\prime}\left(m_{p}^{i}\right)}=\frac{\phi_{i}+\lambda_{i j}-\lambda_{j i} \frac{u^{\prime}\left(m_{p}^{j i}\right)}{u^{\prime}\left(m_{p}^{i}\right)}\left[1-\frac{u^{\prime}\left(\widehat{m}_{p}^{j i}\right)}{u^{\prime}\left(m_{p}^{j i}\right)}\right]}{\phi_{i}+\lambda_{i j}} \forall i .
$$

Since $\lambda_{l h}=0$ rich families are fully insured implying $u^{\prime}\left(\widehat{m}_{p}^{h}\right)=u^{\prime}\left(m_{p}^{h}\right)$. For poor families, we have $\lambda_{h l}>0$ and $u^{\prime}\left(m_{p}^{h l}\right) / u^{\prime}\left(m_{p}^{l}\right)<1$. However, we can not determine whether the expression in brackets is smaller or larger than one, so we can have both more or less than full insurance for low-wealth families. To the extent that $D_{i}$ and $\widehat{D}_{i}$ redistribute and provide insurance, they can be replaced in part by private insurance if that one is available at fair rates. In that case, insurance demand $I$ for the poor must be taxed or subsidized to achieve the appropriate degree of under- or overinsurance.

We summarize our results in the following proposition.

Proposition 4 When parents differ in wealth $\omega_{i}$ (with $\left.i=l, h\right)$ which is - as opposed to all other variables - unobservable to the government, the optimal second-best policy is characterized by:

(i) no distortion of bequests and a zero marginal tax rate for rich families. A downward distortion of bequests and a positive marginal tax rate for poor families.

(ii) the first-best tradeoff for labor supply and informal care which, however, does not translate into zero marginal taxes. Specifically,

a) for rich families we have $T_{\ell}^{h}=\widehat{T}_{\widehat{\ell}}^{h}=1$ and

$$
T_{a}^{h}=h^{\prime}\left(a_{h}\right)+2 \frac{q^{\prime}\left(a_{h}\right)}{u^{\prime}\left(m_{c}^{h}\right)},
$$

which are the same tax rates as in the first-best implementation;

b) for poor families the subsidies on labor supplies and on informal care are smaller than the first-best levels. This is necessary to reestablish a first-best tradeoff in the presence of distortions on bequests.

(iii) full public LTC insurance for rich families and less or more than full insurance for poor families. Private insurance is not necessary to implement the second-best allocation. It can be used in equilibrium only if it is fair. 


\section{Summary and conclusion}

This paper has studied family aid and the demand for LTC in a model of family decision making which is based on Becker's $(1974 ;$ 1991) rotten kid specification. This setting represents in a sense a worst case scenario concerning the "harmony" of family relations. In particular, children are purely selfish and neither side can make credible commitments. In Becker's world, with a single good, this setting yields nevertheless an efficient outcome. In our more complex setting the rotten kids mechanism continues to be at work and ensures that a positive level of aid is provided as long as the bequest motive is operative. In other words, even when children are completely selfish and when parents have no way to credibly commit to a bequest rule (which might for instance "punish" misbehaving children) some aid is provided, but at a level that is likely to be too low. We have analyzed the laissez-faire which is represented by a multi-stage (noncooperative) "aid for bequest" game and we assessed potential sources of inefficiencies by comparing the equilibrium with the efficient solution. Then, we have examined the design of LTC policies under various informational assumption and with both identical and heterogenous individuals. Concerning the latter, we have focused on differences in parent's wealth which introduces a dimension of redistribution in policy design. Specifically, some individuals may be too poor to afford the LTC services they need (or buy the appropriate insurance even when it is fair). Interestingly, these individuals are then subject to a "double jeopardy"; since their resources are depleted in case of dependency, they cannot afford to leave a bequest and accordingly will not receive any aid from their children either. The case for public intervention is then quite strong.

We have obtained a number of specific results characterizing the tax treatment of the relevant variables depending on the informational context. For instance, under full information both aid and labor supply had to be subsidized (the latter to compensate for the implicit tax imposed through the adjustment of bequests). However, when aid was not observable it might be desirable to tax (market) labor as this introduces an implicit subsidy on aid. When parents differ in (unobservable) wealth the optimal policy has been shown to involve a taxation of bequests for some individuals but the tradeoff between labor and aid was left undistorted.

Beyond these specific findings the major lesson that has emerged is that crowding out of aid either by private insurance, or by a public LTC benefit or insurance scheme 
is not a problem in this setting. In families where the bequest motive is operative, aid is unaffected by public benefits. More surprisingly still, when the bequest motive is (originally) not operative (so that no aid is provided), public benefits may even lead to a positive level of aid. In these cases public benefits (or private insurance) and family benefits are actually complements (and no substitutes). Since crowding out of family aid is one of the major concerns in the LTC debate this property has important policy implications. We can obviously not claim that all families interact in the way described in our model. In reality aid is no doubt provided for a wide variety of motives. Children may be altruistic and parents may have a wider variety of instruments (involving some form of commitment) to induce their children to provide aid. Still pure selfishness (or something that closely resembles it) is certainly also at work in many circumstances. Policy design should then be studied in a setting where different types of family exchange patterns coexist. Our analysis is an important building block in such an all encompassing model the development of which represents a formidable challenge. ${ }^{15}$ This is even more so as the optimal policy is then not just a combination of the policies to be adopted under each individual pattern of family relations. Since the degree of intra-family altruism is likely to be private information, the LTC policy may somehow attempt to screen for this unobservable information. For instance, altruistic and non altruistic families are likely to be affected in different ways by the quality of public LTC provision. With these differential preferences, quality of care may be an effective screening devise, not just for wealth but also for the degree of altruism.

Finally, the prevalence of altruism or selfishness in family relations is of course to a large extent an empirical question. From that perspective our analysis is useful in that it points to the significance of crowding out as an indicator of the (very loosely speaking) "degree of harmony" in family relations. Such an avenue has been pursued for instance by Bolin et al. (2008) who argue that their results suggest that in regions with 'strong' family ties, i.e. southern Europe, informal care to a greater extent substitutes for formal home care. Our model not only provides the micro foundations to such claims but it also shows that determining the "average" level of crowding out and (thus altruism) in any given country is only of limited help for policy design. Since different patterns of

\footnotetext{
${ }^{15}$ Ponthière (2013) takes a steph in that direction by considering a setting in which altruistinc and non-altruistic families coexist. In his setting the degree of altruism is not exogenous but follows a socialization process à la Bisin and Verdier (2001). He shows that whether crowding out arises or not depends on individual preferences and on the socialization mechanism at work.
} 
family relations are likely to exist within any given country (though maybe in different country specific proportions) it would be useful to look at crowding out and altruism on a more disaggregate level. Since many data are available on a micro-level we trust that this path could be explored and would represent a useful complement to our analysis. ${ }^{16}$

\section{Appendix}

\section{A Proof of Proposition 2}

To determine the levels of the different instruments we have to revisit the different stages of the game.

\section{A.1 Stage 3}

The optimal bequest in each state of nature is now determined by maximization of

$$
\begin{aligned}
& \max _{\widehat{b}} \widehat{W}_{p}=u(\omega-p I-\widehat{b}-\widehat{D})+u\left(\left(1+\widehat{\tau}_{y}\right) w \widehat{\ell}+\widehat{b}\right)-v(\widehat{\ell}), \\
& \max _{b} \quad W_{p}=u(\omega+(1-p) I-L+h(a)+D-b)+q(a) \\
& +u\left(\left(1+\tau_{y}\right) w \ell+b+\tau_{a} a\right)-v(\ell+a) .
\end{aligned}
$$

The FOCs (8)-(9) continue to apply. Consequently, as long as there is an interior solution for $b$ and $\widehat{b}$ we will automatically have

$$
m_{p}=m_{c} \quad \text { and } \quad \widehat{m}_{p}=\widehat{m}_{c} .
$$

However, the comparative statics change since now we have $\widehat{b}^{*} \equiv \widehat{b}\left(I, \widehat{\ell}, \widehat{\tau}_{y}, \widehat{D}\right)$ and $b^{*} \equiv b\left(I, \ell, a, \tau_{y}, \tau_{a}, D\right)$

$$
\frac{\partial b^{*}}{\partial a}=\frac{h^{\prime}(a)-\tau_{a}}{2}, \quad \frac{\partial b^{*}}{\partial \ell}=-\frac{w\left(1+\tau_{y}\right)}{2}, \quad \frac{\partial \widehat{b}^{*}}{\partial \widehat{\ell}}=-\frac{w\left(1+\widehat{\tau}_{y}\right)}{2} .
$$

\section{A.2 Stage 2}

The child solves

$$
\begin{array}{ll}
\max _{\widehat{\ell}} & \widehat{U}_{c}=u\left(\left(1+\widehat{\tau}_{y}\right) w \widehat{\ell}+\widehat{b}^{*}\right)-v(\widehat{\ell}) \\
\max _{\ell, a} & U_{c}=u\left(\left(1+\tau_{y}\right) w \ell+b^{*}+\tau_{a} a\right)-v(\ell+a) .
\end{array}
$$

\footnotetext{
${ }^{16}$ An alternative empirical strategy to assess the motivation of family aid is used by Norton et al. (2013). Using data from the 1999 and 2003 waves of the National Longitudinal Survey of Mature Women they show that there is significant evidence that caregives are effectively "paid" through inter vivos transfers.
} 
The FOCs with respect to $\widehat{\ell}, \ell$ and $a$ amount to

$$
\begin{aligned}
& \frac{\partial \widehat{U}_{c}}{\partial \widehat{\ell}}=u^{\prime}\left(\widehat{m}_{c}\right)\left(w\left(1+\widehat{\tau}_{y}\right)+\frac{\partial \widehat{b}^{*}}{\partial \widehat{\ell}}\right)-v^{\prime}(\widehat{\ell})=0 \\
& \frac{\partial U_{c}}{\partial \ell}=u^{\prime}\left(m_{c}\right)\left(w\left(1+\tau_{y}\right)+\frac{\partial b^{*}}{\partial \ell}\right)-v^{\prime}(\ell+a)=0 \\
& \frac{\partial U_{c}}{\partial a}=u^{\prime}\left(m_{c}\right)\left(\frac{\partial b^{*}}{\partial a}+\tau_{a}\right)-v^{\prime}(\ell+a)=0 .
\end{aligned}
$$

Comparing (69) and (70) to the corresponding fist-best conditions (3) and (4) shows that the first-best can be decentralized with $\tau_{y}=\widehat{\tau}_{y}=1$, which establishes (29).

Turning to the subsidy on aid, combining (71) with the first-best allocations (5) and (4) shows that $\tau_{a}$ must be chosen such that

$$
u^{\prime}\left(m_{c}\right)\left(\frac{\partial b^{*}}{\partial a}+\tau_{a}\right)=u^{\prime}\left(m_{c}^{f b}\right) h^{\prime}\left(a^{f b}\right)+q^{\prime}\left(a^{f b}\right) \quad \Leftrightarrow \quad \tau_{a}=h^{\prime}\left(a^{f b}\right)+2 \frac{q^{\prime}\left(a^{f b}\right)}{u^{\prime}\left(m_{c}^{f b}\right)},
$$

which establishes (30).

We are now also in a position to determine the levels of $D$ and $\widehat{D}$. Transfers must be designed so that $m_{p}+m_{c}=\widehat{m}_{p}+\widehat{m}_{c}$, which along with the third stage equilibrium condition (65) implies $m_{p}=m_{c}=\widehat{m}_{p}=\widehat{m}_{c}$ and thus (2). This requires

$$
\omega-L+h(a)+D+\left(1+\tau_{y}\right) w \ell+\tau_{a} a=\omega-\widehat{D}+\left(1+\widehat{\tau}_{y}\right) w \widehat{\ell}
$$

In addition, the budget constraint requires

$$
\pi\left[D+\tau_{y} w \ell+\tau_{a} a\right]+(1-\pi) \widehat{\tau}_{y} w \widehat{\ell}=(1-\pi) \widehat{D},
$$

where $\ell, \widehat{\ell}$ and $a$ are set at the FB level (but superscripts are dropped at this stage to simplify notation). The budget constraint can be rewritten as

$$
\widehat{D}=\frac{\pi}{1-\pi}\left[D+\tau_{y} w \ell+\tau_{a} a\right]+\widehat{\tau}_{y} w \widehat{\ell}
$$

Substituting into (72) and rearranging successively yields

$$
\begin{aligned}
D= & (1-\pi)\left\{L+\left(1+\widehat{\tau}_{y}\right) w \widehat{\ell}-\left[\left(1+\tau_{y}\right) w \ell+h(a)+\tau_{a} a\right]\right\} \\
& -\pi\left[\tau_{y} w \ell+\tau_{a} a\right]-(1-\pi) \widehat{\tau}_{y} w \widehat{\ell} .
\end{aligned}
$$

Rearranging (75) and using (74) then establishes (31) and (32).

Finally, note that this solution implies full insurance, it is plain that no additional private insurance will be bought. 


\section{B Proof of Proposition 3}

Making use of equation (21) (which coincides with $\partial \ell^{*} / \partial D$ for $p=0$ ) and (22) (which coincides with $\partial \widehat{\ell^{*}} / \partial \widehat{D}$ for $p=1$ ), equations (36) and (37) reduce to

$$
\frac{u^{\prime}\left(\widehat{m}_{p}\right)}{u^{\prime}\left(m_{p}\right)}=\left(\frac{1-\frac{\partial b^{*}}{\partial \ell^{*}} \frac{\partial \ell^{*}}{\partial D}}{1+\frac{\partial \widehat{b}^{*}}{\partial \widehat{\ell}^{*}} \frac{\partial \widehat{\ell}^{*}}{\partial \widehat{D}}}\right)\left(\frac{1+t w \frac{\partial \widehat{\ell}^{*}}{\partial \widehat{D}^{\prime}}}{1-t w \frac{\partial \ell^{*}}{\partial D}}\right) \Leftrightarrow u^{\prime}\left(\widehat{m}_{p}\right)=u^{\prime}\left(m_{p}\right),
$$

which establishes (i).

To establish (ii) first multiply (36) by $w \ell^{*}$ and (37) by $-w \widehat{\ell^{*}}$ to obtain

$$
\begin{aligned}
& u^{\prime}\left(m_{p}\right)\left(w \ell^{*}-w \ell^{*} \frac{\partial b^{*}}{\partial \ell^{*}} \frac{\partial \ell^{*}}{\partial D}\right)-\mu\left(w \ell^{*}-t w^{2} \ell^{*} \frac{\partial \ell^{*}}{\partial D}\right)=0 \\
& u^{\prime}\left(\widehat{m}_{p}\right)\left(w \widehat{\ell}^{*}+w \widehat{\ell}^{*} \frac{\partial \widehat{b}^{*}}{\partial \widehat{\ell}^{*}} \frac{\partial \widehat{\ell}^{*}}{\partial \widehat{D}}\right)-\mu\left(w \widehat{\ell}^{*}+t w^{2} \widehat{\ell}^{*} \frac{\partial \widehat{\ell}^{*}}{\partial \widehat{D}}\right)=0
\end{aligned}
$$

Adding (76) and (34), and (77) and (35) and simplifying by using (38) and (39) yields

$$
\begin{aligned}
& {\left[u^{\prime}\left(m_{p}\right)\left(h^{\prime}\left(a^{*}\right)-\frac{\partial b^{*}}{\partial a^{*}}\right)+q^{\prime}\left(a^{*}\right)\right] \frac{\partial a^{*}}{\partial t}-\left[u^{\prime}\left(m_{p}\right) \frac{\partial b^{*}}{\partial \ell^{*}} \frac{\partial \ell^{* c}}{\partial t}\right]+\mu t w \frac{\partial \ell^{* c}}{\partial t}=0,} \\
& -\left[u^{\prime}\left(\widehat{m}_{p}\right) \frac{\partial \widehat{b}^{*}}{\partial \widehat{\ell}^{*}} \frac{\partial \widehat{\ell}^{* c}}{\partial t}\right]+\mu t w \frac{\partial \widehat{\ell}^{* c}}{\partial t}=0 .
\end{aligned}
$$

Noting that $\partial \widehat{b}^{*} / \partial \widehat{\ell}^{*}=-(1-t) w / 2$ and rearranging yields (40) and (41).

\section{Second-best: first-order conditions}

Denoting $\mathcal{L}$ the Langrangean function of this problem, the FOCs are given by

$$
\begin{aligned}
\frac{\partial \mathcal{L}}{\partial I_{i}}= & \left(\phi_{i}+\lambda_{i j}\right)\left[\pi(1-p) u^{\prime}\left(m_{p}^{i}\right)-(1-\pi) p u^{\prime}\left(\widehat{m}_{p}^{i}\right)\right] \\
& -\lambda_{j i}\left[\pi(1-p) u^{\prime}\left(m_{p}^{j i}\right)-(1-\pi) p u^{\prime}\left(\widehat{m}_{p}^{j i}\right)\right] \leq 0 \\
\frac{\partial \mathcal{L}}{\partial b_{i}}= & \left(\phi_{i}+\lambda_{i j}\right)\left[u^{\prime}\left(m_{c}^{i}\right)-u^{\prime}\left(m_{p}^{i}\right)\right]-\lambda_{j i}\left[u^{\prime}\left(m_{c}^{j i}\right)-u^{\prime}\left(m_{p}^{j i}\right)\right]=0, \\
\frac{\partial \mathcal{L}}{\partial a_{i}}= & \left(\phi_{i}+\lambda_{i j}\right)\left[u^{\prime}\left(m_{p}^{i}\right) h^{\prime}\left(a_{i}\right)+q^{\prime}\left(a_{i}\right)-v^{\prime}\left(\ell_{i}+a_{i}\right)\right] \\
& -\lambda_{j i}\left[u^{\prime}\left(m_{p}^{j i}\right) h^{\prime}\left(a_{i}\right)+q^{\prime}\left(a_{i}\right)-v^{\prime}\left(\ell_{i}+a_{i}\right)\right]=0 \\
\frac{\partial \mathcal{L}}{\partial \ell_{i}}= & \left(\phi_{i}+\lambda_{i j}\right)\left[u^{\prime}\left(m_{c}^{i}\right) w-v^{\prime}\left(\ell_{i}+a_{i}\right)\right]-\lambda_{j i}\left[u^{\prime}\left(m_{c}^{j i}\right) w-v^{\prime}\left(\ell_{i}+a_{i}\right)\right]=0, \\
\frac{\partial \mathcal{L}}{\partial \widehat{b}_{i}}= & \left(\phi_{i}+\lambda_{i j}\right)\left[u^{\prime}\left(\widehat{m}_{c}^{i}\right)-u^{\prime}\left(\widehat{m}_{p}^{i}\right)\right]-\lambda_{j i}\left[u^{\prime}\left(\widehat{m}_{c}^{j i}\right)-u^{\prime}\left(\widehat{m}_{p}^{j i}\right)\right]=0, \\
\frac{\partial \mathcal{L}}{\partial \widehat{\ell}_{i}}= & \left(\phi_{i}+\lambda_{i j}\right)\left[u^{\prime}\left(\widehat{m}_{c}^{i}\right) w-v^{\prime}\left(\widehat{\ell}_{i}\right)\right]-\lambda_{j i}\left[u^{\prime}\left(\widehat{m}_{c}^{j i}\right) w-v^{\prime}\left(\widehat{\ell}_{i}\right)\right]=0 .
\end{aligned}
$$




$$
\begin{aligned}
& \frac{\partial \mathcal{L}}{\partial D_{i}}=\left(\phi_{i}+\lambda_{i j}\right) u^{\prime}\left(m_{p}^{i}\right)-\lambda_{j i} u^{\prime}\left(m_{p}^{j i}\right)-\mu \phi_{i}=0, \\
& \frac{\partial \mathcal{L}}{\partial \widehat{D}_{i}}=\left(\phi_{i}+\lambda_{i j}\right) u^{\prime}\left(\widehat{m}_{p}^{i}\right)-\lambda_{j i} u^{\prime}\left(\widehat{m}_{p}^{j i}\right)-\mu \phi_{i}=0, \\
& \frac{\partial \mathcal{L}}{\partial T_{i}}=\left(\phi_{i}+\lambda_{i j}\right) u^{\prime}\left(m_{c}^{i}\right)-\lambda_{j i} u^{\prime}\left(m_{c}^{j i}\right)-\mu \phi_{i}=0, \\
& \frac{\partial \mathcal{L}}{\partial \widehat{T}_{i}}=\left(\phi_{i}+\lambda_{i j}\right) u^{\prime}\left(\widehat{m}_{c}^{i}\right)-\lambda_{j i} u^{\prime}\left(\widehat{m}_{c}^{j i}\right)-\mu \phi_{i}=0 .
\end{aligned}
$$

Combining equations (84) and (86), and equations (85) and (87) yields the first-order conditions for the optimal bequests; equations (79) and (82). In other words, as long as bequests are interior, we do not need transfers between children on top of the transfers between parents. That is, we can set either $T_{i}=\widehat{T}_{i}=0$, or $D_{i}=\widehat{D}_{i}=0$.

\section{References}

[1] Barro R.J., "Are Government Bonds Net Wealth," Journal of Political Economy, 1974, 82 (6), 1095-1117.

[2] Becker, G.S., "A Theory of Social Interactions," Journal of Political Economy, 1974, 82 (6), 1063-1093.

[3] Becker, G.S., "A Treatise on the Family," Harvard University Press, Cambridge, 1991.

[4] Bergstrom, T.C., "A Fesh Look at the Rotten Kids Theorem-and Other Household Mysteries," Journal of Political Economy, 1989, $9^{r 7}$ (5), 1138-1159.

[5] Bergstrom, T.C., "Economics in a Family Way," Journal of Economic Literature, 1996, 34, 1903-1934.

[6] Bernheim, B.D., A. Shleifer, and L.H. Summers, "The Strategic Bequest Motive," Journal of Political Economy, 1985, 93 (6), 1045-1076.

[7] Bisin, A., and T. Verdier, "The Economics of Cultural Transmission and the Dynamics of Preferences", Journal of Economic Theory, 2001, 97, 298-319.

[8] Bolin, K., B. Lindgren, and P. Lundborg, "Your Next of Kin or Your Own Career? Caring and Working Among the 50+ Europe," Journal of Health Economics, 2008, 27, 718-738. 
[9] Brown, J.R., and A. Finkelstein, "Why is the Market for Long-Term Care Insurance so Small?," Journal of Public Economics, 2007, 91, 1967-1991.

[10] Bruce, N., and M. Waldman, "The Rotten-Kid Theorem Meets the Samaritan's Dilemma," Quarterly Journal of Economics, 1990, 105, 155-165.

[11] Canta, C., and P. Pestieau, "Long Term Care Insurance and Family Norms," BE Journal of Economics and Applied Policy, 2013, 2.

[12] Cox, D., "Motives for Private Income Transfers," Journal of Political Economy, 1987, 95, 508-546.

[13] Cox, D., and M.R. Rank, "Inter-Vivos Transfers and Intergenerational Exchange," The Review of Economics and Statistics, 1992, 74 (2), 305-314.

[14] Cremer, H., F. Gahvari, and P. Pestieau, "Uncertain Altruism and the Provision of Long-Term Care," mimeo, 2013.

[15] Cremer, H., P. Pestieau, and G. Ponthière, "The Economics of Long-Term Care: A Survey," Nordic Economic Policy Review, 2012, (2), 107-148.

[16] European Commission, "The 2009 Ageing Report," Joint Report Prepared by the European Commission (DGECFIN) and the Economic Policy Committee (AWG), 2009.

[17] Hirshleifer, J., "Shakespeare vs. Becker on Altruism: The Importance of Having the Last Word," Journal of Economic Literature, 1977, 15 (2), 500-502.

[18] Hughes, S.L., A. Giobbie-Hurder, F.M. Weaver, J. Kubal, and W. Henderson, "Relationship Between Caregiver Burden and Health-Related Quality of Life," Gerontologist, 1999, 39 (5), 534-545.

[19] Laferrère, A., and F.-C. Wolff, "Microeconomic Models of Family Transfers," in S.-C. Kolm and J.M. Ythier, eds., Handbook of the Economics of Giving, Altruism and Reciprocity, 1, Amsterdam: Elsevier, 2006, 879-969.

[20] Mirrlees, J.A., "An Exploration in the Theory of Optimum Income Taxation," The Review of Economic Studies, 1971, 38 (2), 175-208. 
[21] Mossin, J., "Aspects of Rational Insurance Purchasing," Journal of Political Economy, 1968, 76 (4), 553-568.

[22] Norton, E., L. Nicholas, and S.S.-H. Huang, "Informal Care and Inter-Vivos Transfers: Results from the National Longitudinal Survey of Mature Women," $B E$ Journal of Economics and Applied Policy, 2013, 2.

[23] OECD, "Long-Term Care for Older People,"Paris: OECD, 2005.

[24] Ponthière, G., "Long-Term Care, Altruism and Socialization", BE Journal of Economics and Applied Policy, 2013, 2.

[25] Schulz, R., and S.R. Beach, "Caregiving as a Risk Factor for Mortality: The Caregiver Health Effects Study," Journal of the American Medical Association, 1999, 282 (23), 2215-2219.

[26] Siciliani, L., "The Economics of Long-Term Care", BE Journal of Economics and Applied Policy, 2013, 2. 